\title{
Vino, actores y tramas: espacios de concertación de políticas en la vitivinicultura argentina
}

\author{
Margarita Moscheni Bustos \\ Universidad Nacional de San Juan \\ margarita.moscheni@gmail.com \\ Juan Jesús Hernández \\ Universidad Nacional de San Juan \\ juan.j.hernandez@inta.gob.ar
}

Resumen: El objetivo general de este artículo es analizar los espacios de concertación existentes en la vitivinicultura argentina en 2019 y las relaciones de poder que se desarrollan en su seno, a partir de la descripción de las organizaciones participantes $y$ excluidas de ellos, los temas tratados y los conflictos y consensos principales.

La metodología es cualitativa. Las fuentes utilizadas son la bibliografía especializada y veinte entrevistas a líderes de las organizaciones del sector vitivinicola y a funcionarios.

Se pretende contribuir a la bibliografía sobre la institucionalidad de la vitivinicultura argentina mediante una descripción de los espacios de concertación actuales liderados por el Estado o por actores del sector privado. Este análisis da cuenta de la reproducción de las asimetrías y conflictos en el mercado vitivinicola en el orden institucional y politico.

Palabras claves: vitivinicultura; políticas; concertación; tramas; actores. 


\section{Wine, Stakeholders and Frameworks: Negotiation Forums in Argentinean Viticulture and Winemaking}

Abstract: The general aim of this study is to analyze the existing negotiation forums of Argentine viticulture in 2019 and the power relations within it. This is carried out through a description of the participating and excluded organizations, the topics they discuss and the main agreements and conflicts. The study follows a qualitative methodology. The sources used are topic-specific literature and 20 interviews of the leaders and officials of organizations in the wine sector.

The findings contribute to the existing literature on the institutional character of Argentinean viticulture and winemaking by providing a specific input on the structure of negotiation forums as the arenas of power intertwined with public policies. This analysis describes the reproduction of the asymmetries and conflicts related to the wine market in the institutional and political order

Keyword: viticulture and winemaking; policies; negotiation; frameworks; stakeholders 


\section{El objetivo y los interrogantes de la investigación}

El objetivo general de este artículo es analizar los espacios de concertación existentes en la vitivinicultura argentina en 2019 y las relaciones de poder que se desarrollan en su seno, a partir de la descripción de las organizaciones participantes y excluidas de ellos, los temas tratados, los recursos que disputan, los conflictos y consensos principales.

Los interrogantes que guían este trabajo son los siguientes: ¿cuáles y de qué tipo son los espacios de concertación existentes?, ¿quiénes participan y quiénes están excluidos en ellos?, ¡‘cómo incide el peso económico y político de los agentes en las tomas de decisiones en esos espacios?, y ¿cuáles son los conflictos y consensos de base existentes en ellos?

Se aspira a aportar un estudio original sobre los espacios de concertación que permita una caracterización más compleja, actual y profunda de la trama política y social de la agroindustria.

\section{Aproximaciones conceptuales al objeto de estudio}

Se entiende por trama institucional al entramado o red de organizaciones que conforman un determinado sector y que se relacionan entre sí. Cada organización, sea formal o informal, está integrada por personas físicas o civiles (empresas, por ejemplo) y podrá adquirir la forma de cámara, asociación, federación, unión, centro, etc. Todas buscan representar intereses corporativos de un subsector de la producción y ejercer influencia en el poder estatal para lograr una mayor cooptación y control de los recursos públicos y privados, obteniendo ventajas respecto a otros grupos que competirán por lo mismo.

De esta manera, se entiende el diseño de políticas públicas no como un tranquilo y neutro espacio jurídico o administrativo (Aguilar Villanueva, 1992: 31), sino más bien como una arena de poder configurada a partir de las intervenciones de actores públicos y privados portadores de recursos.

En las cadenas productivas, como la de la vitivinicultura argentina, la puja principal entre los agentes que participan de las relaciones comerciales es la cooptación del excedente generado. El establecimiento de precios a lo largo de la cadena se realiza a través de relaciones asimétricas entre esos agentes, donde unos tienen más poder que otros para imponer condiciones (precios, calidad, plazos de pago, etc.).

Las organizaciones desplegarán sus recursos para defender los intereses del subsector al que representan, cada una de ellas con poder relativo diferente en función de su nivel influencia sobre las políticas del Estado. La injerencia que 
cada una de las organizaciones ejerza dependerá de la importancia económica y posición (dominante o dominada) en la cadena productiva de la fracción de clase o subsector de la producción al que represente.

Se entiende por políticas estatales (o públicas) a un conjunto de acciones y omisiones que expresan una forma de intervención del Estado sobre una cuestión que concita el interés y movilización de actores de la sociedad civil (Oszlak y O’Donnell, 1984).

Las acciones y omisiones estatales reflejan una trama institucional de intereses que se cristalizan en las instituciones, sea en su fortalecimiento o debilidad. Todo ello es producto de la influencia de diferentes grupos de agentes que confluyen para incidir en los espacios de decisión, problematizando cuestiones, direccionando la agenda pública e incidiendo en la elaboración e implementación de políticas estatales.

Este trabajo abarca principalmente a las organizaciones representativas del capital en el sector vitivinícola argentino, es decir, aquellas propietarias de los medios de producción, pero pertenecientes a fracciones muy distintas en su composición social y posición en los mercados: viñateros, bodegueros elaboradores de vino a granel (o de traslado), fraccionadores, fabricantes de mostos, cooperativas que integran eslabones de la producción, etc.

Alburquerque sostiene que «tanto el sector público como los agentes privados empresariales y el conjunto de la sociedad local, deben ser capaces de abrir espacios de concertación estratégica para construir la institucionalidad políticoadministrativa que respalde el desarrollo local» (Alburquerque, 2004: 16).

Bebbington, Delamaza y Villar (2006) afirman que, en esos espacios, actores con diferentes identidades e intereses se encuentran para discutir sus diferencias, sabiendo que podrán concertar solo en algunos temas. Aunque sirven para acordar, estos ámbitos también se caracterizan por asimetrías de información, poder y conflictos.

Para Remy (2005) en estos espacios se debe observar cómo se construye el consenso, quiénes participan, qué representantividad existe, cómo se define la agenda, y cómo toman las decisiones en última instancia quienes gobiernan.

Los espacios de concertación en América Latina suelen estar liderados o copados por las élites o actores fuertes, quedando fuera los sectores más pobres o peor organizados, por lo que sus demandas o intereses no suelen ser atendidos o no forman parte de la agenda de trabajo. Además, al ser limitados los recursos de los que se dispone para decidir algunos actores se muestran desinteresados o abandonan estos espacios al no ver atendidas sus prioridades (Hintze Martínez, $2016: 31-32)$. 
En este artículo los espacios de concertación se definen como ámbitos de negociación, diálogo y participación en los que los grupos involucrados toman posición frente a los temas de agenda, realizan acuerdos y compromisos explícitos o tácitos e intentan influir sobre las políticas públicas. En ellos los individuos tienen alianzas, consensos, conflictos y tensiones con otros agentes privados y estatales, y no todos los miembros tienen las mismas capacidades en el ejercicio del poder. El Estado se considera como un actor más, que solo en ocasiones convoca o lidera, pero siempre conserva el privilegio del monopolio de la coerción.

En los espacios de concertación el empresariado expresa sus disímiles intereses, pero puede generarse una «homogenidad construida», en términos de Lissin (2008).

Los contextos de crisis de la economía facilitan las posibilidades de confluir en torno a intereses comunes y de lograr consensos - aunque sean transitorios, parciales, frágiles y fruto de negociaciones- que aumentan el poder de lobby o influencia del empresariado sobre las políticas públicas. Esto supone que los sectores del capital precisan organizarse coletivamente para progresar y defender sus intereses, ya que la homogeneidad entre ellos no viene dada a priori. La homogenidad construida se configura y se alcanza en el desarrollo de procesos económicos y políticos concretos e históricamente situados, responde a una necesidad estratégica, política coyuntural de las corporaciones, y no elimina del todo la heterogenidad de interes (Lissin, 2008: 20).

Cada espacio de concertación adquirirá características distintas dependiendo de varias dimensiones.

Una primera se refiere al sector que convoca al diálogo. Si bien todos los actores pertenecen a un mismo sector o actividad económica - la agroindustria vitivinícola en este trabajo-, algunos representarán al Estado, predominando su rol de funcionarios públicos, y otros, desde una lógica más mercantil, a las cámaras empresariales. Para unos y otros los objetivos podrían ensamblarse a mediano plazo, pero en el tiempo más inmediato en los espacios convocados por una organización estatal el objetivo principal de los funcionarios es legitimar su política, consolidar la agenda y lograr los apoyos que se requieren de las fracciones económicas para garantizar la gobernabilidad. Por su parte, los dirigentes empresariales buscarán hacer lobby en los funcionarios, influir en la agenda, tener acceso a los recursos del presupuesto y a los beneficios de las políticas estatales, accediendo a ventajas diferenciales respecto del resto de los agentes de otras fracciones del capital.

Por otro lado, se encuentran los espacios convocados o liderados por instituciones privadas cuyo objetivo más inmediato es lograr, con sus pares, acuerdos 
corporativos que configuren las condiciones de un determinado territorio económico, evitando temas específicos en los que se develen las diferencias y contradicciones de intereses. Para esta dimensión es posible preguntarseः ¿cuáles son los espacios de concertación en los que se vinculan los agentes privados y gubernamentales interesados en el crecimiento de una actividad económica?, ¿cómo pueden clasificarse?, y ¿qué propósitos persigue cada uno?

Una segunda dimensión en el estudio se refiere a los actores que componen cada espacio de concertación, y en la figura de ellos es clave analizar los intereses que representan. El extremo en la clasificación podrá ir desde espacios en los que predominan los agentes estatales a otros que son mayoritariamente ocupados por privados, $y$, tal como se abordó en el párrafo anterior, tendrán objetivos distintos. Asimismo, dada la heterogeneidad en la composición del capital, en los espacios privados es importante examinar el rol que ocupan los agentes dominantes en la actividad económica y la posibilidad de voz y voto que tengan los miembros originarios de las fracciones dominadas. En la vitivinicultura argentina los primeros estarían representados por los empresarios que elaboran subproductos de la cadena vitícola con un alto componente tecnológico y destinados al mercado externo, y los segundos, por agentes que producen bienes de baja calidad enológica y comercializados a granel (uva y vino de traslado). También podrían identificarse posiciones intermedias expresadas por aquellas organizaciones del empresariado nacional que producen y fraccionan vinos de mediana o alta calidad para consumidores finales en el mercado interno. Para esta dimensión es posible preguntarse lo siguiente: ¿cuáles son los actores que intervienen en cada espacio de concertación?, ¿a qué fracción representa y qué intereses tienen?, y ¿quiénes están ausentes en tales espacios?

Una tercera dimensión para el estudio de los espacios de concertación se refiere a los temas que predominan en la agenda, comprendiendo un amplio abanico que puede ir desde aspectos estrictamente técnicos hasta cuestiones comerciales, económicas o políticas. Los interrogantes aquí son los siguientes: ¿qué temas predominan en la agenda de cada espacio? y ¿qué organización o fracción es capaz de incluir o excluir temas?

Una cuarta dimensión se refiere a los recursos económicos que circulan por los espacios, particularmente en lo que respecta al financiamiento para su creación y al destino de los recursos materiales, en el caso de que los haya. Podría suponerse a priori que las organizaciones integradas por agentes de fracciones dominantes son las que tengan mayor influencia en la decisión sobre los gastos en los espacios de concertación. Algunas cuestiones a responder son quién financia los espacios de concertación, cómo se decide el destino de esos fondos y a quién 
beneficia, y si existe homogeneidad de intereses entre las fracciones dominantes o hay temas que permiten que emerjan sus diferencias.

Una quinta dimensión está asociada a la anterior y se refiere a la temporalidad de los espacios, algunos serán coyunturales o esporádicos y otros requerirán de mayor estabilidad en el tiempo. Los interrogantes aquí son los siguientes: ¿los espacios son coyunturales o estables? y ¿qué hitos promueven la creación de algunos o la desaparición de otros?

\section{La metodología}

El presente artículo es un trabajo de nivel exploratorio con un enfoque cualitativo, cuyo fin es comprender e interpretar las características de los espacios de concertación en una determinada actividad económica, y no generalizar sus resultados.

La categoría central del trabajo es «espacios de concertación», y será abordada a través de las siguientes dimensiones: actores que convocan y lideran, actores predominantes y subordinados, temas que predominan en la agenda, recursos que circulan por los espacios y temporalidad (reuniones esporádicas o frecuentes).

El principal supuesto que guía este trabajo es que las organizaciones que representan a las fracciones dominantes en el mercado son las de mayor incidencia en los espacios de concertación, reproduciendo de esa manera las asimetrías propias del mercado económico en la arena política.

Para el análisis se utiliza una metodología cualitativa, con un abordaje interpretativo. Se trabajó con fuentes secundarias (bibliografía académica especializada que se cita) y primarias, particularmente veinte entrevistas realizadas a dirigentes de las organizaciones del sector vitivinícola nacional y a funcionarios de los Gobiernos provinciales, que han permitido caracterizar los espacios de concertación, citándose alguna de sus frases en comentarios a pie de página.

Las entrevistas a esos informantes clave fueron abiertas y semiestructuradas. La muestra de dirigentes fue intencional y el criterio de selección de las unidades de observación comprendió las siguientes variables:

La organización que representa el entrevistado (dominantes, dominadas, presentes y ausentes). Se eligió este criterio a los efectos de abarcar las voces de mayor frecuencia en los espacios de concertación pero también las que en esos mismos ámbitos quedan subordinadas o están excluidas.

+ El eslabón de la cadena vitivinícola al que pertenecían sus miembros (primario, secundario o terciario).

- El subproducto dentro del circuito productivo y el destino (uva, vino, mosto), ya que no es lo mismo producir uva o vino común para venta a granel que vino fraccionado o mostos para exportación. 
+ El sector del que provienen (estatal, privado), a los efectos de conocer los propósitos y las lógicas de actuación de cada uno.

- De acuerdo con estos criterios, los entrevistados fueron los siguientes:

- Presidente del Consejo de Enólogos de San Juan.

+ Vicepresidente del Instituto Nacional de Vitivinicultura.

- Ministro de Producción y Desarrollo Económico de San Juan.

- Miembro del directorio de COVIAR y presidente de CAPROVIT.

- Jefe de Gabinete del Ministerio de Economía de Mendoza.

- Expresidente del Instituto Nacional de Vitivinicultura.

+ Abogada, especialista en legislación vitivinícola.

- Gerente de Bodegas de Argentina.

+ Gerente general de la Corporación Vitivinícola Argentina.

+ Gerente de la Unión Vitivinícola Argentina.

+ Presidente de Bodegas de Argentina.

- Presidente de la Asociación de Viñateros Independientes de San Juan.

- Presidenta de la Asociación de Productores del Este de Mendoza.

- Presidente de la Cámara de Bodegueros de San Juan.

- Presidente de la Federación de Viñateros de San Juan.

- Presidente de la Unión Vitivinícola Argentina.

- Presidente de la Cámara Argentina de Fabricantes y Exportadores de Mosto.

+ Dirigente de FECOVITA-ACOVI.

- Presidente de la Cámara Vitivinícola de San Juan.

+ Presidente de la Asociación de Viñateros de Mendoza.

\section{Los actores de la vitivinicultura argentina}

Desde mediados del siglo $\mathrm{xx}$, la vitivinicultura argentina creció por el aumento del consumo de vinos comunes a nivel nacional. Las bodegas elaboraban vinos generalmente indiferenciados y baratos (Hernández, 2017). En el último cuarto de siglo, el consumo per cápita manifestó una constante reducción, pasando de 88 litros en 1977 hasta llegar a menos de 20 litros en la actualidad. La estrategia empresarial para afrontar la nueva etapa consistió en generar una profunda reconversión con el cultivo de variedades de uvas finas, la incorporación de nuevas tecnologías en viñedos y bodegas, la exportación, la diferenciación de productos 
para ser dirigidos a una amplia gama de clientes, el aumento de la producción de pasas y mostos, y el surgimiento de nuevas actividades conexas como la gastronomía en fincas y bodegas o el enoturismo (Dulcich, 2016; Moscheni, 2013; Gennari, Estrella Orrego y Santoni, 2013).

La globalización y la apertura de los mercados favorecieron especialmente a aquellos actores que lograron la integración en la cadena, mejoraron sus procesos de producción y su tecnología y se especializaron en la elaboración de vinos de calidad o mostos, orientados a la exportación. Las ventas al exterior de vinos argentinos se incrementó sustancialmente desde la década de los noventa, sin embargo, al mercado interno se destina todavía más del 70\% del volumen de elaboración anual.

La provincia de mayor producción vitivinícola es Mendoza, seguida luego por San Juan y por otras de volúmenes muy inferiores (La Rioja, Salta, Catamarca, Neuquén, Río Negro, etc.). Los mercados nacionales se caracterizan por la existencia de oligopolios de bodegas con capacidad de envasado, especialmente en los vinos comunes, la paulatina expulsión de los pequeños viñateros que no logran rentabilidad y la importancia cada vez mayor del eslabón comercializador (supermercados y otros canales).

Los agentes vitivinícolas tuvieron a lo largo del siglo $\mathrm{xx}$ gran propensión a la asociación en cámaras, gremios u otro tipo de organizaciones que se encargaron de la defensa de los intereses de sectores específicos.

Las principales organizaciones representativas de los agentes del sector privado de la vitivinicultura argentina son las siguientes:

a) Cámara de Bodegueros de San Juan: representa a los industriales más importantes de esa provincia, que venden en el mercado interno o exportan.

b) Bodegas de Argentina: representa a los grandes bodegueros del país, en especial de Mendoza. Sus socios alcanzan ventas en el mercado interno de alrededor del $60 \%$ de lo que se consume en envases de cartón (tetra brik) y del $85 \%$ del vino que se vende en botella. En el mercado externo representan el 90\% de la exportación de vinos fraccionados (Bodegas de Argentina, 2018).

c) Cámara Vitivinícola de San Juan: tiene alrededor de noventa socios, la mayoría de las cuales son empresas elaboradoras de vino de traslado y de mosto sulfitado (Moscheni, 2014).

d) Unión Vitivinícola Argentina (UVA): representa a industriales nacionales integrados en la cadena con diversos volúmenes de producción que en su mayoría venden en el mercado interno.

e) Asociación de Cooperativas Vitivinícolas (ACOVI): surge en 1961 y sus afiliados pertenecen en su mayor parte a FECOVITA, que es una coope- 
rativa de segundo grado que nuclea a 29 cooperativas de viñateros. Es uno de los actores principales de la economía de Mendoza y uno de los líderes en la producción de vino de gama media y baja que se comercializa en el mercado interno.

f) Centro de Viñateros y Bodegueros del Este de Mendoza: creado en 1946, está conformado fundamentalmente por bodegas que carecen de capacidad de envasado de los vinos que elaboran, de manera que venden a granel vinos de baja o media calidad.

g) Cámara Argentina de Exportadores de Mostos: nuclea a los agentes concentradores y exportadores de mostos.

j) Federación de Viñateros de San Juan: se creó en 1954 para la defensa de los intereses de los agentes primarios no integrados de esta provincia. Tradicionalmente se caracterizó por ser una institución con un importante poder de movilización pero con baja influencia en los Gobiernos provinciales y nacionales (Moscheni, 2014).

k) Asociación de Viñateros de Mendoza: fue fundada en 1944, cuenta en la actualidad con alrededor de 500 asociados, la mayoría de los cuales poseen explotaciones de menos de 10 ha, y algunos de ellos venden a las cooperativas de FECOVITA (Román, 2018).

1) Asociación de Viñateros Independientes de San Juanः tiene más de 500 miembros, en general viñateros no integrados.

m) Cámara de Productores Vitícolas (Caprovit): es la organización más nueva en la matriz social de San Juan, ya que se creó en 2004, a partir de un grupo de productores que participaron en la formulación del Plan Estratégico Argentina Vitivinícola (PEVI) 2020.

n) Cámara Riojana de Productores Agropecuarios (CARPA) : es una entidad gremial empresaria de la provincia de La Rioja, que agrupa a la mayoría de las empresas vitivinícolas locales, además de otros rubros productivos.

o) Otras organizaciones son la Federación de Cámaras de Productores Vitícolas, la Asociación de Productores del Este de Mendoza (APROEM), la Asociación de Productores en Acción (APA), también de Mendoza, y algunas entidades departamentales de esa provincia que nuclean a productores de diversas agroindustrias.

p) Los principales sindicatos donde se agrupan los trabajadores de la vitivinicultura son la Federación de Obreros y Empleados Vitivinícolas y Afines (FOEVA) y la Unión Argentina de Trabajadores Rurales y Estibadores (UATRE), que tiene afiliados de diversas actividades agrarias.

q) Los enólogos tienen representación en el Centro de Enólogos de Mendoza y en el Consejo Profesional y Centro de Enólogos de San Juan. 
r) El Instituto Nacional Vitivinícola (INV) es el órgano estatal fiscalizador de la calidad de los productos de la agroindustria, que forma parte de la estructura del Estado nacional. Tiene una comisión asesora con participación de algunas organizaciones del sector privado.

s) Además se puede mencionar al Instituto Nacional de Tecnología Agropecuaria (INTA), que es un organismo de ciencia y tecnología del Estado nacional.

La vitivinicultura tiene un denso entramado institucional, con una importante diversidad que refleja la heterogeneidad de la agroindustria.

La multiplicidad de organizaciones existentes constituye un buen indicador de la heterogeneidad de intereses presentes y también es expresión de las dificultades que existen para que los actores sientan que sus intereses son representados por una única entidad. La cantidad de agrupamientos, además, dificulta profundamente la unificación espontánea de los intereses (la «homogeneidad dada»), dejando como camino único la «homogeneidad construida» (Lissin, 2008) en espacios de concertación.

\section{Los espacios de concertación. ¿Dónde se toman las decisiones en el escenario vitivinícola?}

En este trabajo, los espacios de concertación se clasifican en dos grupos: a) los convocados y liderados por el Estado, y b) los de carácter privado-público. La diferencia radica en quién convoca y en quién lidera, más allá de quiénes participan o están excluidos, a veces son los mismos actores.

\subsection{Espacios convocados por el Estado}

$\mathrm{Su}$ origen es una convocatoria del Gobierno nacional o de los Gobiernos provinciales, ya sea formal, a través de una ley, por ejemplo, o informal, es decir, sin mediar instrumento jurídico que establezca temas o pautas de trabajo

La agenda está determinada por temas coyunturales, es decir, problemas actuales cuya resolución debe ser inmediata. En general, su naturaleza es política, y está vinculada a la legitimación o el asesoramiento de las decisiones de los funcionarios.

En estos espacios no hay un compromiso de convocatoria periódica o fechas fijas de reuniones. El Estado suele aparecer como un receptor de opiniones o demandas. Son espacios en los que los funcionarios realizan una selección estratégica sobre los temas en los que se deberá tomar decisiones y sobre los grupos convenientes para hacer alianzas y acuerdos. Los recursos que se disputan tienen 
que ver con la financiación de las políticas públicas que se van a implementar desde los ministerios del Poder Ejecutivo nacional o provincial.

Las convocatorias suelen abarcar a casi todas las organizaciones de empresarios, excluyéndose las de trabajadores. Los temas tratados van desde la presentación y definición de detalles de políticas públicas para la agroindustria hasta la gestación de acuerdos por el precio de la uva, control de plagas, entre otros. La opinión de las cámaras de bodegueros tiene un peso importante en estos espacios.

Desde 2015 a 2019 han existido en la vitivinicultura argentina cuatro espacios de concertación de este tipo: dos con origen en el Estado nacional y dos en las principales provincias productoras. A continuación se analiza cada uno de ellos.

\subsubsection{Mesa de Competitividad Nacional}

La Mesa de Competitividad fue creada por el Ministerio de Agroindustria de la Nación en 2016 (hoy Ministerio de Agricultura, Ganadería y Pesca) para tratar temas de la vitivinicultura. Los participantes son todas las organizaciones del sector privado que conforman la Corporación Vitivinícola Argentina (COVIAR), otras entidades que también son invitadas (p. ej., Federación de Viñateros de San Juan) y referentes de los Gobiernos provinciales con producción vitivinícola. En uno de los encuentros participó el presidente de la nación.

La importancia de la mesa radica en tener como interlocutores a las autoridades del Gobierno nacional. Las reuniones realizadas han tenido un temario y orden de la palabra previamente establecidos por el ministerio.

Los referentes del sector vitivinícola entrevistados la calificaron como un ámbito de diálogo y escucha, pero con bajo impacto político, por la falta de atención de las demandas expresadas. Ellos entienden que se ha dado un paso adelante con su creación, que es bueno que el Gobierno nacional convoque y que no es suficiente abrir espacios de diálogo, sino que hace falta, además, tener interlocutores estatales que conozcan las particularidades de esta agroindustria ${ }^{1}$. Un representante de una organización bodeguera sostuvo incluso que en este espacio impera la lógica política, de «quedar bien con todos», lo que implica que sean reuniones masivas de pocas consecuencias efectivas.

Por ejemplo, en 2017, uno de los temas abordados fue la estrategia para combatir la extensión de una plaga que afecta a la vid, denominada Lobesia Botrana,

1 «Las economías regionales no tienen un especialista en el Gobierno nacional, no tienen con quién hablar, nadie entiende mínimamente la lógica, que sí lo tienen las áreas lecheras o de granos, tienen tipos que saben, que conocen, que están en contacto. En el tema vitivinícola no hay un director de vitivinicultura, ni un tipo especializado en la nación» (entrevista a un referente vitivinícola para esta investigación). 
para lo cual el Estado nacional otorgó una importante financiación que el año siguiente retiró para que fuera asumida por los Gobiernos provinciales.

En 2019, sobre el final del mandato del Gobierno nacional, el espacio perdió importancia, dada la escasa cantidad de recursos que se ponían en discusión y su fuerte dependencia de la voluntad de convocatoria de funcionarios para los cuales la vitivinicultura no es la agroindustria prioritaria en el país.

\subsubsection{Mesa de Consenso Vitivinícola de San Juan}

El Gobierno de San Juan denomina Mesa de Consenso a un espacio que convoca para temas puntuales, del que participan las organizaciones de viñateros y bodegueros con base en esa provincia. Según los entrevistados, aquí se suelen manifestar disidencias, a la vez que puede servir para acordar, transmitir información y facilitar el contacto entre los referentes. No existe una normativa que institucionalice su existencia, participantes, fechas de reuniones o temas posibles a tratar.

Tiene como objetivo abordar temas coyunturales o estratégicos, además de aportar al equilibrio de las relaciones de fuerza propias de la vitivinicultura local, en particular de los actores que no participan formalmente de otros espacios de concertación. Por ejemplo, integran la mesa de consenso provincial la Federación de Viñateros y la Asociación de Viñateros Independientes, que no participan en COVIAR.

Los recursos que se ponen en juego dependen de la decisión de los funcionarios. En general ha servido para comunicar o construir decisiones de gobierno ( $\mathrm{p}$. ej., subsidios o créditos a la producción), o brindar un espacio institucional para la discusión de temas clave, como los precios de la uva.

\subsubsection{Espacio convocado por el Gobierno de Mendoza}

El Gobierno de Mendoza tiene un espacio de concertación muy similar al del Gobierno de San Juan, que carece de nombre específico y de fechas fijas de reuniones. En la provincia existen organizaciones por zonas, lo que complejiza la convocatoria. Los temas tratados suelen ser de política vitivinícola provincial. Son invitadas todas las entidades locales pero su asistencia efectiva depende de la sensibilidad del tema en agenda ( $p$. ej, aumenta si se tratan temas tributarios según uno de los entrevistados).

Las organizaciones que no tienen una presencia activa en COVIAR, como el Centro de Viñateros y Bodegueros del Este, encuentran en esta mesa la posibilidad de incrementar su peso político e incidir sobre las políticas públicas. 


\subsubsection{Comisión Asesora Técnica del INV}

En 1993 se creó, en el seno del INV, la Comisión Técnica Asesora del Sector Privado, conformada por representantes del Instituto y de organizaciones de empresarios de San Juan, Mendoza y La Rioja.

Esta comisión (cuyo nombre varió con los años, aunque mantiene la esencia de su integración) es un espacio convocado por un organismo del Estado nacional al que asisten enólogos o ingenieros de las organizaciones cuando se tratan temas técnicos. En cambio, cuando los temas son de gran importancia política o económica, suelen estar presentes las principales autoridades.

Los entrevistados mencionaron se convoca alrededor de tres veces al año y tiene un carácter técnico-enológico, fundamentalmente.

La Comisión tiene funciones de simple asesoría al presidente del INV, quien tiene el poder de decisión en última instancia. Más que un espacio para construir hegemonía, resulta una instancia de legitimación o consulta de decisiones en las que no se dirimen recursos económicos directamente, aunque las decisiones técnicas sobre la elaboración de productos tendrán impacto sobre los costos de las empresas, por lo cual son especialmente tenidas en cuenta las posiciones de las organizaciones de bodegueros.

\subsection{Espacios de concertación privado-públicos}

El segundo grupo está integrado por los espacios de concertación privado-públicos. El orden de los términos es relevante porque denota qué sector tiene participación mayoritaria y poder de decisión.

Los actores del sector privado lideran estos espacios, que se encuentran institucionalizados mediante una norma legal que crea una entidad con personería jurídica específica de la que participan algunas organizaciones de empresarios y algunos niveles del Estado.

La financiación proviene del sector privado total o principalmente, pero tiene garantías de cobro y/o cofinanciación del Estado, respaldadas en su poder coercitivo.

La agenda de estos espacios está vinculada a cuestiones estructurales que ameritan planificación y acciones a mediano y largo plazo. Ello no quiere decir que los temas coyunturales no sean tratados, pero solo se abordan si se ha logrado un consenso previo entre los agentes, a través de alianzas y negociaciones.

Esos consensos funcionan como base y origen del espacio, y también como factor de exclusión para los agentes que los cuestionan o no se adhieren a ellos. Una vez establecidos los temas a tratar y ciertos lineamientos, quienes no acuerdan suelen retirarse, de manera que así se tiende a invisibilizar los conflictos y la 
entidad creada adquiere estabilidad sobre la base de alianzas parciales. La hegemonía construida es indispensable aunque precaria.

Las decisiones tomadas tienen legitimidad en tanto provienen de varias organizaciones que han llegado a un acuerdo. La misma entidad supraorganizacional se convierte en un nuevo actor para el sector e incluso en un interlocutor ante el Estado, adquiriendo influencia sobre las políticas públicas.

Los principales líderes del sector privado entrevistados afirmaron que tratar cuestiones en las que haya consenso es la clave para la sostenibilidad de estos espacios. Por ello los temas son seleccionados en función de las posibilidades concretas de conseguir acuerdos, a riesgo de dejar de lado otros temas más polémicos y estratégicos para la agroindustria. Así, por ejemplo, el precio de la uva, que es clave en la agroindustria, no aparece en estos ámbitos porque implicaría posicionamientos contradictorios entre las organizaciones de viñateros y bodegueros que probablemente no tendrían resolución y podrían generar la ruptura del espacio.

Las organizaciones de viñateros participan, pero no todas, y en un rol subordinado. Las organizaciones de enólogos y de trabajadores están excluidas. El liderazgo lo adquieren las organizaciones de actores integrados en la cadena, que cuentan con bodegas con capacidad de envasado y hasta viñedos. El Estado, al estar en minoría en los directorios que se encargan de la conducción, tiene un rol subalterno a pesar de haber dado la base jurídica y la garantía de financiación.

Las cámaras empresariales, especialmente las de los empresarios nacionales que elaboran y fraccionan vinos para el mercado interno, utilizan estos espacios para manejar recursos, gestionar conflictos entre ellas y legitimar su poder y accionar.

Podemos mencionar dos espacios de concertación privado-públicos que se analizan a continuación.

\subsubsection{Corporación Vitivinicola Argentina (COVIAR)}

Tras la crisis de la economía argentina en 2001 y las nuevas posibilidades de exportación que se abrieron a partir de la devaluación, la mayoría de las organizaciones del sector, bajo la convocatoria del INTA, confluyeron en la formulación del Plan Estratégico Vitivinícola Argentina 2020 (PEVI).

Para su implementación en 2003 se creó la COVIAR, ente público no estatal que está conducido por un directorio conformado por representantes de ACOVI, Asociación de Viñateros de Mendoza, Bodegas de Argentina, UVA, Centro de Viñateros y Bodegueros del Este, Cámara de Exportadores de Mosto, Cámara de Bodegueros de San Juan,; Cámara Vitivinícola de San Juan, productores de 
uvas de mesa y pasas de San Juan, CARPA, Federación de Cámaras de Productores Vitícolas y un representante del sector privado por las demás provincias productoras. Por el sector público tienen lugar en el directorio el INV, el INTA, los Gobiernos de Mendoza y San Juan y un representante que se alterna entre los Gobiernos de La Rioja, Catamarca, Salta, Neuquén y Río Negro.

Los programas de la Corporación responden a los objetivos del $\mathrm{PEVI}^{2}$ y se realizan a través de unidades ejecutoras. De esta forma también se pretende fortalecer el entramado socioinstitucional existente (Ruíz y Vitale, 2011: 45). Esa estructura en la actualidad da cuenta, por ejemplo, de un Observatorio Vitivinícola para recabar datos de producción en coordinación con la Bolsa de Comercio de Mendoza, de programas para la promoción de los vinos argentinos en el exterior y de los Centros de Desarrollo Vitícolas para el asesoramiento y conformación de grupos de productores en conjunto con INTA ${ }^{3}$.

Para financiar las actividades se instituyó una contribución obligatoria, a cargo de todos los establecimientos vitivinícolas, además de otras fuentes de financiación, de las cuales la más importante fue un préstamo del Banco Interamericano de Desarrollo (BID) para un programa de integración de viticultores ${ }^{4}$.

La COVIAR fue considerada por los entrevistados como el principal espacio de concertación debido a distintos factores.

El primero es la forma estatuida para el financiamiento; el aporte obligatorio refuerza el compromiso y la participación de los actores del sector privado ${ }^{5}$, además de otorgarle a la Corporación cierta independencia respecto al Estado, ya que no depende de manera exclusiva de la financiación estatal. Más allá de que ese aporte sea muchas veces cuestionado por las empresas individuales, que suelen identificarlo casi como un impuesto más (Chazarreta, 2012 74).

En segundo lugar, la creación a través de una ley nacional (N. $\left.{ }^{\circ} 25849 / 2003\right)$ otorga estabilidad, personería jurídica, personal contratado exclusivamente dedicado y respaldo estatal tanto al PEVI como a COVIAR.

En tercer lugar, la alternancia sistemática de la presidencia de la Corporación entre los representantes del sector privado de distintas provincias cada tres años, sin posibilidades de reelección, favorece la circulación del poder. De hecho, la

2 Los tres objetivos del PEVI fueron la inserción de los vinos varietales argentinos en los mercados del norte, el reimpulso del mercado argentino y latinoamericano, y la integración de los pequeños productores.

3 «Hoy en COVIAR hay muchas cámaras que no tienen estructura o tienen muy poca estructura. Entonces ¿de dónde sacan recursos y gente para hacer cosas? De la COVIAR» (entrevista a un dirigente de COVIAR).

4 «El BID nos ha dado un préstamo directamente a la COVIAR cuando el BID solo da préstamos a Gobiernos nacionales, provinciales cuando se trata de estados federales y municipales, y es la primera vez que le da a una institución de orden público pero no es estatal. Por supuesto que ha sido una condición que ha sido que sea la nación la garantía de la aplicación de ese programa» (entrevista a un dirigente bodeguero).

5 «Aquí hay que cambiar la realidad y si no ponemos guita es un club de amigos» (entrevista a un referente de la industria). 
presidencia siempre ha sido ejercida por los líderes de las entidades de productores, elaboradores de vino de traslado o cooperativistas (Chazarreta, 2014: 71). A pesar de no haber ejercido nunca la presidencia, Bodegas de Argentina, ACOVI y UVA tienen una gran importancia en el directorio, donde suelen asistir a las reuniones tantos sus presidentes como sus gerentes generales, reproduciendo en el organismo el poder que tienen sus afiliados en los mercados ${ }^{6}$.

Un cuarto elemento es la igualdad en la votación establecida por ley, a pesar de la heterogeneidad del sector. De esta manera, la opinión de las organizaciones que representan a empresas que lideran la facturación del mercado vitivinícola argentino tiene el mismo peso que el de las demás. Aunque es preciso señalar que en toda la historia de esta institución solo se han tomado dos decisiones vía votación: la elección del gerente general y la actualización del aporte obligatorio en 2009. En la realidad, el mecanismo de toma de decisiones generalmente aplicado es el consenso.

Chazarreta (2014: 72) se pregunta sobre la COVIAR qué habilita el consenso y por qué parece ser una práctica positivamente significada por sujetos con intereses diferentes o incluso a veces antagónicos. Aquí la autora recupera el concepto de hegemonía construida de Lissin (2008).

Esta homogeneidad no excluye la existencia de una heterogeneidad de intereses, ya que la misma se constituye por una necesidad estratégica política de las entidades gremiales-empresariales. Ciertamente, existen elementos que ponen en cuestión la idea de consenso y unidad en la misma corporación [Sin embargo], estos temas que enfrentan a los distintos sectores de la burguesía encuentran otros espacios de discusión, es decir quedan fuera del ámbito de incumbencia de la COVIAR [... ]. Ello obedece a la importancia otorgada por estos mismos sectores a este espacio como diferenciado de los existentes, donde se puedan trazar políticas de largo plazo para la actividad (Chazarreta, 2014: 73-74).

Un quinto elemento que refuerza la institucionalidad de COVIAR es la participación de organismos estatales de diferentes instancias: tres Gobiernos provinciales, el INV y el INTA como referente de ciencia y tecnología.

La institucionalidad del sector cambia desde la organización de sus actores en COVIAR, se genera un contrapeso a los Gobiernos y se amplía la independencia del sector, quebrando el vínculo típico del «empresario pidiendo y el Estado dando desde el mostrador», según la expresión de un dirigente entrevistado.

6 «La COVIAR nació para llevar a cabo un plan estratégico, y un plan estratégico era tratar de ver cómo al pequeño productor se lo podía integrar en la cadena, y nació con esa idea, pero, por ejemplo, fue copada por los sectores grandes de la industria, los que manejaban la industria en la época de Menem son los mismo que manejan hoy la COVIAR» (entrevista a dirigente de una organización que no participa de COVIAR). 
Para los sectores de la burguesía vitivinícola nacional y, en particular, el sector cooperativo, este espacio de concertación permite posicionarse ante el Estado como un bloque con amplia representación (Chazarreta, 2014: 75)

La importancia política de la Corporación se traduce en la influencia que ejerce sobre decisiones estatales. Por ejemplo, sus gestiones lograron que se sancionara la ley que establece al vino como «bebida nacional», se evitara el establecimiento de un impuesto interno al vino, no prosperaran los proyectos de regulación de plantaciones de vid y se creara un sistema de devolución de parte del impuesto a las exportaciones de la agroindustria vigente durante algunos años.

Esos logros son más apreciables que los alcanzados en el cumplimiento de los objetivos plan, por lo que, según algunos entrevistados, subyace la posibilidad de transformar al organismo en una entidad de tercer grado, que se dedique a la representación de las entidades que nuclea ante el poder político. Sin embargo, esta idea no ha ganado consenso y no ha sido tratada oficialmente por el directorio ${ }^{7}$.

Los productores vitícolas tienen participación en COVIAR a través de CAPROVIT, Asociación de Viñateros de Mendoza, la Federación de Cámaras Vitícolas y las entidades que representan a los agentes integrados, especialmente ACOVI para el sector cooperativo. No integran la corporación otras organizaciones del sector primario que no se sumaron al plan estratégico en el momento de su formulación: Federación de Viñateros de San Juan, Asociación de Viñateros Independientes y APROEM. Sus líderes en las entrevistas mencionaron que su interés es que en este espacio se traten los temas referidos a la formación de precios en las cadenas de valor; sin embargo, según el análisis de este trabajo, es justamente la exclusión de esos temas polémicos lo que facilita el surgimiento, continuidad y estabilidad de la Corporación.

La falta de participación de algunas organizaciones es un tema polémico, especialmente en San Juan, porque la Federación y la Asociación de Viñateros tienen más afiliados que CAPROVIT, que es miembro del directorio de COVIAR en representación del sector, tras haber sido designada en ese rol por el Gobierno provincial ${ }^{8}$.

\footnotetext{
7 «Nuestros socios tienen en claro que cuando nos pagan a nosotros pagan por un problema coyuntural y cuando ven que la COVIAR hace otra cosa se preguntan qué están haciendo con esto de la coyuntura, si yo ya pago la coyuntura, yo te estoy pagando para que hagas estructura. Deberíamos repensar una COVIAR que no se dedique a los temas de coyuntura, que no se dedique a tantas cosas, que se dedique a pocas cosas y pensemos en la vitivinicultura que viene dentro de tantos años» (entrevista a un dirigente bodeguero).

8 La ley de creación de COVIAR, 25.849/2003, estableció que, para San Juan, la representación sería efectuada por un miembro titular de la Cámara de Bodegueros, uno de la Cámara Vitivinícola de San Juan y un representante de Productores Vitícolas y de productores de uvas de mesa y pasas; estas últimas se indicaron de manera genérica, ya que no es la denominación de ninguna cámara u organización en particular El decreto reglamentario 1191/2004 precisó que esos lugares serían definidos por el Ministerio de Producción e Inversiones de dicha provincia. El enfrentamiento de la Federación y la Asociación de Viñateros con el Gobierno provincial derivó
} 
Tampoco tienen representación en COVIAR otros actores del concierto vitivinícola, como los sindicatos, las entidades profesionales de enólogos o el eslabón de la comercialización. En algunas entrevistas se mencionó que sería importante sumarlos.

Hasta 2015, si bien existían diferencias internas en la Corporación, prevalecía una imagen pública de consenso y unidad entre los integrantes (Chazarreta, 2019: 21), que aparecía ante otras agroindustrias como un modelo (Bocco et alii, 2007).

En los últimos años se profundizaron las diferencias entre los miembros del directorio que amenazan la continuidad del organismo.

En primer lugar, dejó de participar en las reuniones el Centro de Viñateros y Bodegueros del Este de Mendoza, manifestando sus diferencias con las grandes entidades que nuclean a las bodegas que manejan el precio de la uva y el vino de traslado.

En 2019 surgieron dos conflictos más. Uno por los avances en el acuerdo entre el Mercosur y la Unión Europea para un tratado de libre comercio, que incluye al sector vitivinícola: Bodegas de Argentina apoyó la iniciativa por las posibilidades que abre a sus afiliados, que exportan, principalmente, vinos finos, mientras que la mayoría del directorio se expresó oficialmente en contrario por el riesgo que implica abrir el mercado nacional a la importación de vinos europeos. El segundo conflicto se gestó ante la elaboración del nuevo PEVI con horizonte 2030 en el que se manifestaron disidencias en cuanto a la metodología de apertura a la participación de los actores y a la priorización de objetivos.

En ambos enfrentamientos, se demostró la diferencia entre el sector empresarial, que elabora los mayores volúmenes y nuclea a las bodegas con capacidad para la exportación (y, por lo tanto, paga las mayores contribuciones al plan), liderado por Bodegas de Argentina, que demanda que la COVIAR se oriente a fortalecer la competitividad internacional, especialmente de vinos finos, y otro grupo liderado por ACOVI y UVA, cuyos afiliados tienen sus principales inversiones en el mercado interno.

Estas situaciones le han restado representatividad a COVIAR y han debilitado profundamente la hegemonía construida por el sector empresario, dejando de manifiesto la heterogeneidad de intereses.

en la formación y designación para conformar la COVIAR de CAPROVIT. Sumado a ello, el representante del sector pasero designado fue un productor que, además, es miembro de una tradicional familia bodeguera. 


\subsubsection{Fondo Vitivinícola}

El Fondo Vitivinícola de Mendoza (FVM) es un espacio de concertación privado-público en el ámbito de una provincia. Es una entidad pública no estatal, cuya misión es promover el consumo del vino en Argentina, la difusión de su cultura y el crecimiento de la actividad, a través de estrategias y acciones de comunicación.

El FVM fue creado por la Ley provincial $\mathrm{N}^{\circ} 6.216$ para administrar los fondos que surgen por el Acuerdo San Juan-Mendoza, que comprometió a las provincias para que las empresas radicadas en sus territorios elaboren mostos o exporten vinos en porcentajes acordados anualmente, que si los incumplen deben abonar una contribución. En San Juan no se constituyó un fondo similar, porque el crecimiento de la producción de mostos llevó a que se sobrecumplieran los porcentajes que se establecían.

Participan del FVM: ACOVI; Asociación de Viñateros de Mendoza; Cámara Argentina de Fabricantes y Exportadores de Mosto; Cámara de Agricultura, Industria, Comercio y Ganadería del Valle de Tupungato; Cámara de Comercio, Industria y Agricultura de Tunuyán; Cámara de Comercio Industria y Agropecuaria de San Rafael; Cámara de Comercio, Industria, Agricultura y Ganadería de General Alvear; Cámara Empresaria de Rivadavia; Gobierno de Mendoza, y UVA.

La presencia estatal es ínfima en el FVM, lo que conlleva el predominio del sector privado, con un número considerable de entidades departamentales que tienen afiliados que no son exclusivamente de la agroindustria vitivinícola.

El FVM se dedica a temas estructurales y definidos. Sus actividades son la organización de eventos y ferias, capacitaciones y desarrollo de campañas de promoción del consumo de vinos.

Luego de un proceso de debate interno sobre la estrategia a adoptar, se impuso un criterio de promoción del consumo masivo y genérico del vino en lugar de la sola promoción del vino fino. Esta última decisión distanció a Bodegas de Argentina del organismo y fortaleció la posición de la UVA, que hoy es la principal entidad del sector privado que participa, junto con ACOVI. 


\section{Algunas conclusiones $₫$ las características del entramado institucional}

El presente trabajo partió de algunos interrogantes básicos que se fueron abordando sobre los espacios de concertación existentes, la relación entre el peso económico y político de los agentes en la toma de decisiones y los conflictos y consensos existentes.

Podemos concluir que la vitivinicultura argentina presenta un entramado social heterogéneo que está compuesto por numerosas y diversas organizaciones.

Debido a la heterogeneidad de la agroindustria y la necesidad de lograr acuerdos entre actores del sector privado y consensos para las políticas públicas, se han creado espacios de concertación, comprendiendo que el trabajo en conjunto arroja mejores resultados y que la hegemonía no viene dada, sino que demanda procesos de construcción.

El Estado está presente en los orígenes de los espacios de concertación y se inserta en ellos, ya sea con poder decisorio en última instancia (espacios convocados por el Estado) o como una parte más, dejando la conducción y la mayor proporción del poder en las organizaciones privadas (espacio privad-público). La participación estatal dota de legalidad, legitimidad y recursos a estos ámbitos.

Los espacios de concertación son entonces arenas de poder en las que se concreta la búsqueda de equilibrios y donde existen el conflicto y la negociación constante.

Las organizaciones representativas de fracciones dominantes (bodegas que elaboran grandes volúmenes y cuentan con capacidad de envasado) tienen mayor y mejor participación en los espacios de concertación respecto a las fracciones de viñateros que quedan subordinadas, por su ausencia, invisibilización o debilidad. El segundo grupo a veces ni aparece en las reglamentaciones internas como un miembro estable, suele tener voz pero no voto y sus recursos son menores. De la misma manera, la participación en los eslabones de mercado con mayor margen de ganancia es alta en los miembros del primer grupo y mucho menor en los del segundo. Es decir, se produce un paralelismo institucional entre política y mercado: aquellos que mayor poder tienen en el plano de la acumulación son también los más poderosos en el plano político-institucional, de manera que se comprueba el supuesto del que partió este trabajo.

Los espacios de concertación son especialmente aprovechados por las cámaras de empresarios nacionales para aumentar su incidencia sobre las políticas públicas. Por ejemplo, UVA y ACOVI en los espacios privado-públicos.

La dinámica de la toma de decisiones, basada en alianzas, consensos y acuerdos previos, junto con la exclusión de algunos de los actores más débiles del cir- 
cuito productivo (p. ej., sindicatos y algunas entidades de viñateros), hace que el conflicto de intereses quede silenciado en algunos espacios de concertación, aunque sea por algún período de tiempo.

La existencia de espacios donde se llegue a acuerdos no garantiza una equitativa distribución del poder. Los consensos en las reuniones suelen lograrse sobre la base de la exclusión previa de los agentes disidentes y de los temas en los que existen divergencias.

Esas exclusiones son transitorias. Las disputas entre las entidades que apoyan medidas proteccionistas del mercado interno y las que prefieren la apertura por su mayor capacidad para competir ha generado recientemente una nueva escisión dentro de COVIAR, que es la misma que existió desde el origen en el FVM, que demuestra los distintos modelos de desarrollo de la vitivinicultura en pugna.

Para finalizar se pueden plantear dos nuevos interrogantes para futuros trabajos de investigación: ¿̇ómo se puede construir un espacio de concertación que contribuya a la equidad y redistribución de poder entre los actores de la cadena productiva y sus organizaciones representativas?, y ¿cómo se pueden gestionar los conflictos de tal modo para dotar de estabilidad y permanencia a los tiempo a esos espacios?

La hegemonía construida, aunque siempre parcial e inestable, es deseable que se construya con la participación del mayor número posible de actores y con especial consideración de los trabajadores y pequeños productores, que en el caso de la vitivinicultura ocupan un rol subalterno. 


\section{Bibliografía}

Aguilar Villanueva, L. (1993). Problemas públicos y agenda de gobierno. México: Miguel Porrúa Ed.

Alburquerque, F. (2004). El enfoque del desarrollo económico local. Buenos Aires: Organización Internacional del Trabajo.

Bertranou, J. (2011)."Estado y agencias público-privadas en la promoción del desarrollo productivo en la provincia de Mendoza". Documentos y aportes en administración pública y gestión estatal, 11 (17), 7-40.

Bebbington, A.; Delamaza, G. y Villar, R. (2005). “El desarrollo de base y los espacios públicos de concertación local en América Latina”. Debate Agrario, 40 (41), 299-324.

Bocco, A.; Dubbini, D.; Rotondo, S. y Yogüel, G. (2007). "Reconversión y empleo en la industria del vino. Estructura productiva y dinámica de empleo en el complejo vitivinícola: un análisis del sector bodeguero nacional." $V$ Jornadas Interdisciplinarias de Estudios Agrarios y Agroindustriales. Buenos Aires: FCE-UBA.

Bodegas de Argentina (2018). Sitio web oficial. Disponible en: < www.bodegasdeargentina.org $>$.

Cámara de Bodegueros de San Juan (2018). Sitio web oficial. Disponible en: <http://camaradebodegueros.org/\#!/-bienvenido/>.

Chazarreta, A. (2014). "Los cambios en la organización gremial de la burguesía vitivinícola de la provincia de Mendoza, Argentina (1990-2011)”. Pampa (10), 55-85.

Chazarreta, A. (2019)."Transformaciones recientes de la actividad vitivinícola argentina y avance del agronegocio, 1990-2010”. Revista Latinoamericana de Estudios Rurales, 4 (7).

Dulcich, F. (2016). "Reestructuración productiva en un contexto de apertura y desregulación: la industria vitivinícola argentina ante los desafíos de la reducción de escala." H-industri@, 10 (18),79-105.

Gennari, A.; Orrego, E. y Santoni, L. (2013). "Wine market regulation in Argentina: past and future impacts." AAWE Working Paper, (136), 2-33.

Hernández, J. (2017). “El Instituto Nacional de Vitivinicultura en el periodo 1976-1989: sus políticas y los conflictos por el acceso a sus cargos directivos". En Delia De la Torre (coord.). Estado, economía y sociedad en la provincia de San Juan. Periodo 1976-1989. San Juan: UNSJ.

Hintze Martínez, C. (2016). El rol de los espacios de concertación y la participación ciudadana en el desarrollo local: el caso del distrito de Paucartambo-Cusco, entre los años 2007-2012. Lima: Pontificia Universidad Católica del Perú. 
Lissin, L. (2008). "Acción colectiva empresaria. ¿Homogeneidad dada o construida? Un análisis a la luz de las corporaciones empresarias en la crisis del 2001". Documentos de investigación social, (3), 1-30.

Moscheni, M. (2014). "Tensiones en la relación capital-capital. El caso de los agentes vitivinícolas en San Juan". Estudios Rurales, (7), 35-60.

Oszlak, O. y O’Donnell, G. (1984). Estado y Politicas Estatales en América Latina: hacia una estrategia de investigación. Alcalá de Henares: INAPCLAD-PNUD.

Remy, M. (2005). Los múltiples campos de la participación ciudadana en el Perú. Un reconocimiento del terreno y algunas reflexiones. Lima: IEP Ediciones.

Román, J. (2018). "Política, corporaciones y trayectoria organizacional de pequeños productores y bodegueros en la zona este de Mendoza, Argentina (1980-2017)". RIVAR Revista Iberoamericana de Vitivicultura, Agroindustria y Ruralidad, 4 (13), 141-157.

Ruíz, A. y Vitale, J. (2011). Prospectiva y estrategia: el caso del Plan Estratégico Vitivinícola 2020 (PEVI). Mendoza: Ediciones INTA. 